\title{
An empirical study exploring the determinants of stress among medical healthcare professionals
}

\author{
Amna Anjum¹, Ali Anjum², Umaira Anjum³, Xu Ming ${ }^{1}$
}

\begin{abstract}
1. Donghua University Yan'an Xi Lu Campus, Glorious Sun School of Business and Management.
2. Services Hospital Lahore, Department of Psychiatry.

3. Fatima Memorial Hospital, Department of Family Medicine.
\end{abstract}

\begin{abstract}
Background: Medical profession is considered as one of the stressful professions. Work related stress level among the general working population is around $18 \%$ while the stress level among the healthcare practitioners is around $28 \%$. Multiple stressors contribute to the stress of doctors resulting in negative consequences.

Objective: The objective of the current study was to determine, categorize and to rank the existing stressors according to their significance for medical healthcare professionals in Pakistan.

Method: A self-administered questionnaire was used to collect data from 327 doctors. $47.2 \%$ were males while $52.8 \%$ were females. A structured questionnaire was developed and convenience sampling technique was applied to collect the data from the different positions of healthcare professionals. Exploratory factor analysis (EFA) was performed to categorize and to analyse the underlying structure of stressors. Finally, the stressors were ranked according to their significance.

Results: Appropriateness of factor model was judged through Kaiser, Meyer and Olkin (KMO) index which was 0.905, and by Bartlett's Test of Sphericity which resulted significant (Approx. Chi- Square= 1111.529, Df $=136$, Sig. $=0.000$ ). Seventeen stressors were converted into four categories by factor analysis and were supported by both scree plot and eigen values. The variance explained by the first, second, third and fourth component was $20.89 \%, 19.09 \%, 16.33 \%$, and $11.72 \%$ respectively. The 4 components cumulatively explained $68.03 \%$ of the total variability in the data, hence supported the extraction of 4 components. Conclusion: There are number of factors which enhance the stress of healthcare professionals. In Pakistan, the major stressor of medical healthcare professionals is "career \& reward prospects" followed by "workplace environmental stressor". "Job demand \& performance stressor" ranks third among the list of stressors and "interpersonal stressor" ranks fourth according to significance for healthcare professionals.
\end{abstract}

Keywords: Stress, stressors, medical healthcare professionals, Pakistan.

DOI: https://dx.doi.org/10.4314/ahs.v19i4.31

Cite as: Anjum A, Anjum A, Anjum U, Ming X. An empirical study exploring the determinants of stress among medical healthcare professionals. Afri Health Sci.2019;19(4):3091-3099. https:// dx.doi.org/10.4314/abs.v19i4.31

\section{Introduction}

In recent decades, stress has been getting attention from researchers, academicians, social scientists, medical practitioners and even managers because organizational stress has not only negative impact on organisations but also on the well-being of individuals. Doctors' occupation is considered the most stressful and the primary reason behind the high stress in this field is the sense of responsibility as people and their lives are involved in it. The study of

\section{Corresponding author: \\ Amna Anjum, \\ Donghua University \\ Yan'anlu Campus, Glorious Sun School \\ of Business and Management \\ Email: amnaeem14@gmail.com}

Firth-Cozens1 has shown a higher level of stress among doctors as compared to the general population. He noted that doctors had shown a high level of stress of about $28 \%$ as compared to about $18 \%$ in the general working population ${ }^{1}$. The job stress experienced by health-care workers significantly affects the quality of medical services provided. Indeed, continued exposure to high level of job stress among health care professionals is of great concern not only because it involves ongoing personal suffering but also because it may threaten the quality of patient care $^{2-7}$.

The survey by the Royal College of Anaesthetists found that $64 \%$ of the doctors felt their job had affected physical health while $61 \%$ of the doctors felt that their job had a negative effect on their mental health. Stress symptoms
African
Health Sciences

3091

(C) 2019 Anjum et al. Licensee African Health Sciences. This is an Open Access article distributed under the terms of the Creative commons Attribution License (https://creativecommons.org/licenses/BY/4.0), which permits unrestricted use, distribution, and reproduction in any medium, provided the original work is properly cited. 
adversely affect health, even though one might not realize them. Indeed, stress not only affects the body, thoughts and feelings but it may also influence the behaviour of an employee. Previous studies found that stress is significantly linked with many health problems, such as high blood pressure, heart disease, obesity, diabetes, muscle tension, chest pain, fatigue or sleep problems. Stress also affects professionalism which can be observed through lack of motivation, irritability, anger, sadness, depression, social withdrawal or presenteeism. Being able to recognize the stressors can help us to manage the stress.

Lazarus \& Folkman conceptualises stress as resulting from an imbalance between demands and resources but there is a lack of focus on the role of enduring personality characteristics and emotions in the stress process ${ }^{8}$. $\mathrm{Shah}^{9}$ found that being a doctor is stressful as it demands the physical and mental involvement of doctors and this situation is even more critical in Asian context especially in South Asian Countries which are highly populated and lack in resources. Shah listed different individual stressors in the context of Pakistan but he didn't categorize and rank those stressors according to their significance. Thus, the present study aims to fill the gap and contribute in the existing literature of healthcare professionals.

In Pakistan, physician density per 1000 patients is less than one and this cause work overload on the medical practitioners. There are thousands of doctors which are registered in Pakistan Medical and Dental Council (PMDC) ${ }^{12}$ but in reality most of them are not working in Pakistan. Some of them have left their jobs while others have switched to different professions. There is no available official information about the number of licensed doctors currently working in Pakistan, medical practitioners that have moved abroad for better opportunity, doctors that have changed their profession, and female doctors who have not continued in their profession after marriage?. In Pakistan, approximately 10,000 medical students graduate each year from all 5 provinces, but in the recent years, some negative trends have been seen, such as quitting the profession or serving in some other coun$\operatorname{tr} \mathrm{y}^{10,11}$. The reasons behind this phenomena are the different types of stressors. Taking this into consideration, the present study tries to explore the existing stressors of healthcare practitioners while considering the data from big as well as small cities of Pakistan. This study considered a wide range of stressors and also included different positions of healthcare professionals in Pakistan.
The subject of stress among doctors has a rich theoretical and empirical background in the Western world, but few studies have been conducted in the context of Pakistan. The present study aimed to categorize the existing stressors of medical healthcare professionals and to rank them according to their significance in the context of Pakistan. Having said that, it is not easy to study all stress factors in one study, we identified the significant factors which should be immediately taken into account.

\section{Materials and methods \\ Subjects}

In the current study, the sample consisted of 327 participants from different big and small cities of Pakistan including 173 females and 154 males. Sample was constituted by 49 consultants (15\%), 21 specialist registrars (6.3\%), 113 postgraduate trainees $(34.6 \%), 134$ medical officers $(40.98 \%)$ and 10 demonstrators $(3.12 \%)$.

\section{Data collection}

Data was collected into two steps. In the first step, a questionnaire was developed based on the information gained from the interviews, observations and also with the review of the literature ${ }^{13,14}$. Focus group interviews were conducted from different medical practitioners which included two consultants, two specialist registrars, three postgraduate trainees, three medical officers and two demonstrators to know about their existing stressors. During focus group interviews, broad questions based on the review of the literature were asked to elicit responses and to generate discussion among the participants. Follow-up questions were also asked to delve into deeper discussion. This helped in generating the maximum amount of discussion and opinions. Based on the information gained from focus group interviews, literature and observation, a questionnaire was developed with an internal consistency of 0.917 (Cronbach's alpha).

In the second step, the developed questionnaire was distributed among the respondents and convenience sampling technique was applied. In research, it would be ideal to test the entire population, but in most cases, the population is just too large that it is impossible to include every individual. Many researchers prefer this technique because it is fast, inexpensive, easy and the subjects are readily available. It is the most common of all sampling techniques and is also useful in documenting a particular quality of a substance or phenomenon that occurs within a given sample. Thus, 350 questionnaires were distribut- 
ed. Since we excluded all those questionnaires who had missing responses, only 327 questionnaires were useable. Hence, the response rate was $93 \%$. Data collected was processed by statistical software SPSS.

\section{Measures}

A total of 17 sources of stress were listed which were government policies for doctors, slow promotion process, service structure, employment opportunities, inadequate office facilities, career prospects, workload, time pressure, no positive feedback for good work, difficulty in balancing work-home life, inadequate staffing, overtime work, lack of participation in decision making, harassment, working relationships, gender discrimination and pay level. EFA was performed to understand the underlying structure of stressors and to reduce the data into a smaller set of variables.

\section{Factor analysis}

In factor analysis, principal component analysis with varimax rotation was conducted to assess how seventeen "stressors" clustered into different variables.

Kaiser-Meyer-Olkin (KMO) and Bartlett's Test of Sphericity was applied along with the Principal Component Method for factors extraction based on Eigen values greater than 1.

\section{Results}

EFA result showed that the sample was appropriate for factor analysis since the KMO measure of sampling adequacy was 0.905 which is above the recommended value of $0.70^{16}$. Although, there are different ways to judge the sample appropriateness, the sample selection could be based on different factors. In this study, we used the sample size keeping in mind the "objectives of study" and "the type of statistical test to be applied". As the main objective of the study was to categorize the individual stressors into groups (factors) for which EFA was a suitable statistical test, thus data was processed for 327 respondents. Previous studies showed that the sample size greater than 250 is considered good for EFA and also, in the current study, KMO value was found to be 0.905 which verified the marvellous sample adequacy according to threshold values. The threshold values for KMO are given below for reference15:

$\begin{array}{ll}\text { - } & 0.00 \text { to } 0.49 \text { unacceptable. } \\ \text { - } & 0.50 \text { to } 0.59 \text { miserable. } \\ \text { - } & 0.60 \text { to } 0.69 \text { mediocre. } \\ \text { - } & 0.70 \text { to } 0.79 \text { middling. } \\ \text { - } & 0.80 \text { to } 0.89 \text { meritorious. } \\ & 0.90 \text { to } 1.00 \text { marvellous. }\end{array}$

- $\quad 0.00$ to 0.49 unacceptable.$$
0.60 \text { to } 0.69 \text { mediocre. }
$$$$
0.70 \text { to } 0.79 \text { middling. }
$$$$
0.90 \text { to } 1.00 \text { marvellous. }
$$

Table 1. KMO and Bartlett's Test

\begin{tabular}{llr}
\multicolumn{3}{c}{ KMO and Bartlett's Test } \\
Kaiser-Meyer-Olkin Measure of Sampling Adequacy. \\
\begin{tabular}{llr}
\hline Bartlett's Test of Sphericity & Approx. Chi-Square & .905 \\
\cline { 2 - 3 } & Df & 1111.529 \\
\cline { 2 - 3 } & Sig. & 136 \\
\hline
\end{tabular}
\end{tabular}

\section{Eigen Values and Scree Plot}

A scree test was also used to identify the optimum number of factors and confirmed the findings of retaining 4 factors as the scree plot flattened out after the $4^{\text {th }}$ component. This supported the decision that 17 variables could be reduced to 4 components. 


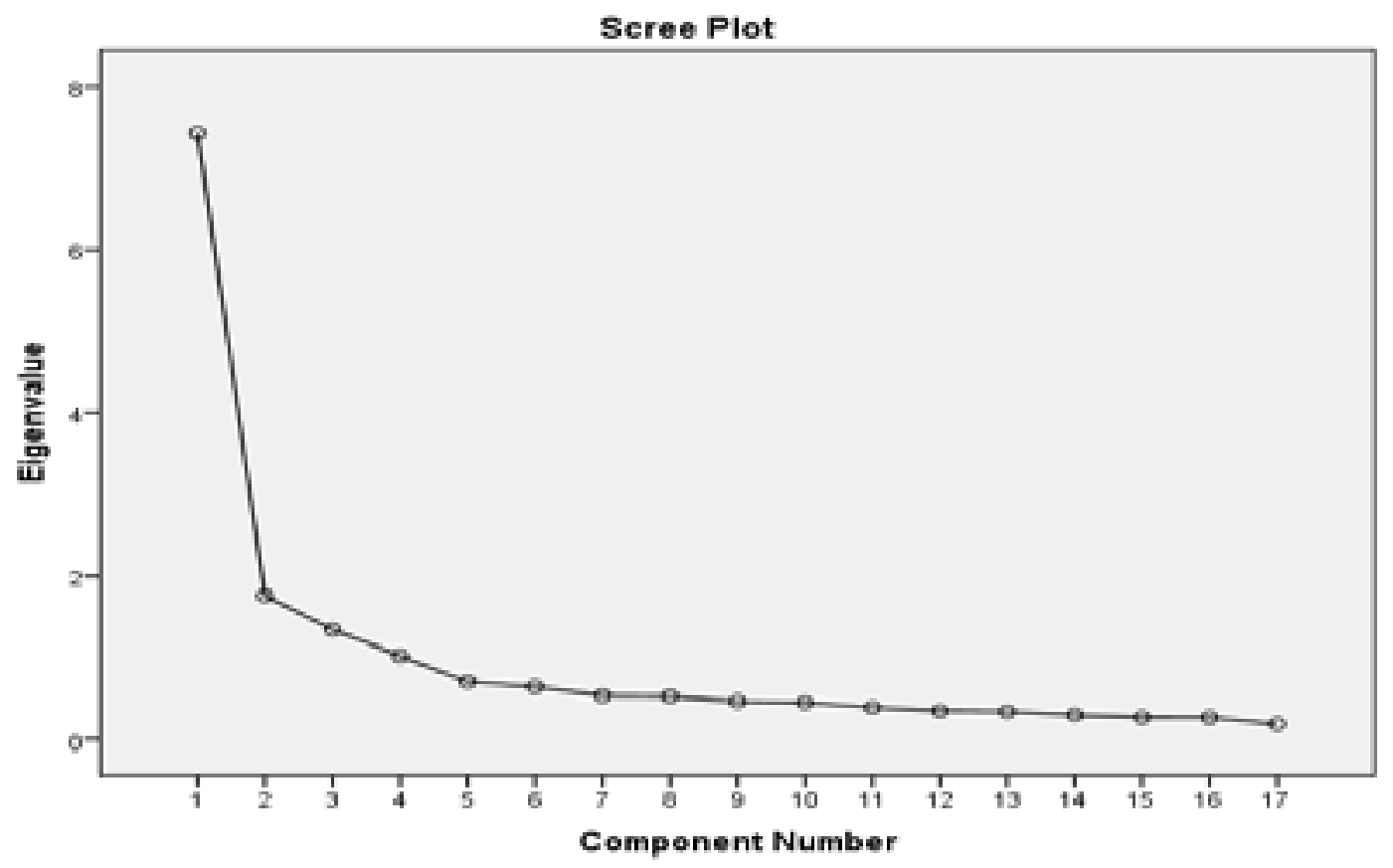

Figure 1:

\section{Total variance explained}

The total variance explained was used to confirm the number of components. Table 2 shows how the variance was divided among the 17 possible components. This table also shows that 4 components have Eigen values greater than 1.0, which is a common criterion for a component to be useful. These four components cumulatively explained $68.03 \%$ of the total variability in the data, hence supported the extraction of the four components.

Table 2. Total Variance Explained

\begin{tabular}{|c|c|c|c|c|c|c|c|c|c|}
\hline \multirow[b]{2}{*}{ Component } & \multicolumn{3}{|c|}{ Initial Eigenvalues } & \multicolumn{3}{|c|}{ Extraction Sums of Squared Loadings } & \multicolumn{3}{|c|}{ Rotation Sums of Squared Loadings } \\
\hline & Total & $\%$ of Variance & Cumulative \% & Total & $\%$ of Variance & Cumulative \% & Total & $\%$ of Variance & Cumulative \% \\
\hline 1 & 7.437 & 43.746 & 43.746 & 7.437 & 43.746 & 43.746 & 3.551 & 20.890 & 20.890 \\
\hline 2 & 1.762 & 10.365 & 54.111 & 1.762 & 10.365 & 54.111 & 3.246 & 19.093 & 39.983 \\
\hline 3 & 1.347 & 7.921 & 62.032 & 1.347 & 7.921 & 62.032 & 2.775 & 16.326 & 56.309 \\
\hline 4 & 1.020 & 5.997 & 68.029 & 1.020 & 5.997 & 68.029 & 1.992 & 11.720 & 68.029 \\
\hline 5 & .704 & 4.141 & 72.170 & & & & & & \\
\hline 6 & .642 & 3.777 & 75.947 & & & & & & \\
\hline 7 & .537 & 3.161 & 79.108 & & & & & & \\
\hline 8 & .531 & 3.122 & 82.230 & & & & & & \\
\hline 9 & .465 & 2.734 & 84.964 & & & & & & \\
\hline 10 & .452 & 2.661 & 87.625 & & & & & & \\
\hline 11 & .393 & 2.314 & 89.939 & & & & & & \\
\hline 12 & .348 & 2.048 & 91.986 & & & & & & \\
\hline 13 & .339 & 1.996 & 93.982 & & & & & & \\
\hline 14 & .299 & 1.757 & 95.739 & & & & & & \\
\hline 15 & .270 & 1.587 & 97.326 & & & & & & \\
\hline 16 & .268 & 1.575 & 98.901 & & & & & & \\
\hline 17 & 187 & 1.099 & 100.000 & & & & & & \\
\hline
\end{tabular}

Extraction Method: Principal Component Analysis. 
Extraction Method: Principal Component Analysis.

The rotated component matrix (Table 3) attempted to translate 17 stressors into 4 components. Each of the components showed the respective loadings. Loadings less than .30 were omitted to improve clarity. These loadings gave us an understanding of the underlying structure of different stressors in the dynamics of job stress.

Table 3. Rotated Component Matrix ${ }^{a}$

\begin{tabular}{|c|c|c|c|c|c|}
\hline 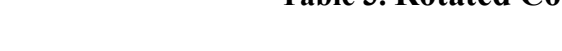 & \multicolumn{4}{|c|}{ Component } & \multirow[b]{2}{*}{ Communalities } \\
\hline & 1 & 2 & 3 & 4 & \\
\hline Workload & .862 & & & & .804 \\
\hline Time pressure & .824 & & & & .722 \\
\hline Inadequate staffing & .700 & & & & 669 \\
\hline Difficulty in balancing work-home life & .676 & & & & .633 \\
\hline Overtime work & .669 & & & & .711 \\
\hline Employment opportunities & & .713 & & & 697 \\
\hline Slow promotion process & & .701 & & & .664 \\
\hline Pay level & & .696 & & & .732 \\
\hline Government policies for doctors & & .650 & & & 625 \\
\hline Service structure & & .643 & & & 663 \\
\hline Career prospects & & .633 & & & 622 \\
\hline No positive feedback for good work & & & .761 & & 690 \\
\hline Lack of participation in "Decision Making" & & & .759 & & 689 \\
\hline Inadequate office facilities & & & .644 & & .667 \\
\hline Gender discrimination & & & & .817 & .731 \\
\hline Harassment & & & & .616 & 721 \\
\hline Working relationships & & & & .554 & .541 \\
\hline Cronbach's alpha & 0.870 & 0.858 & 0.805 & 0.801 & \\
\hline
\end{tabular}

\section{Profiling and interpreting factors: \\ Factor 1}

Factor loadings were high for workload and time pressure. The corresponding communality values were also quite satisfactory and more than $72 \%$ was explained by these factors. So, this factor was called the "job demand and performance stressors".

\section{Factor 2}

Factor loadings were high for employment opportunities, slow promotion process and pay level. Communality powers for these factors were greater than $66 \%$. So, this factor was profiled as "career and reward prospects".

\section{Factor 3}

Factor loadings were high for no positive feedback for good work and lack of participation in decision making. These two factors seem to be quite related to the management style which is an indicator of the work environment. So, this factor was categorized as "workplace environmental stressor".

\section{Factor 4}

Factor loadings were high for gender discrimination and harassment in the fourth component. The communalities for these components were greater than $72 \%$ which is quite enough for profiling. As gender discrimination and harassment encompass negative attitudes and behaviours of individuals so, this factor was named as "interpersonal stressors".

Figure 2 shows the underlying structure of 4 components: 

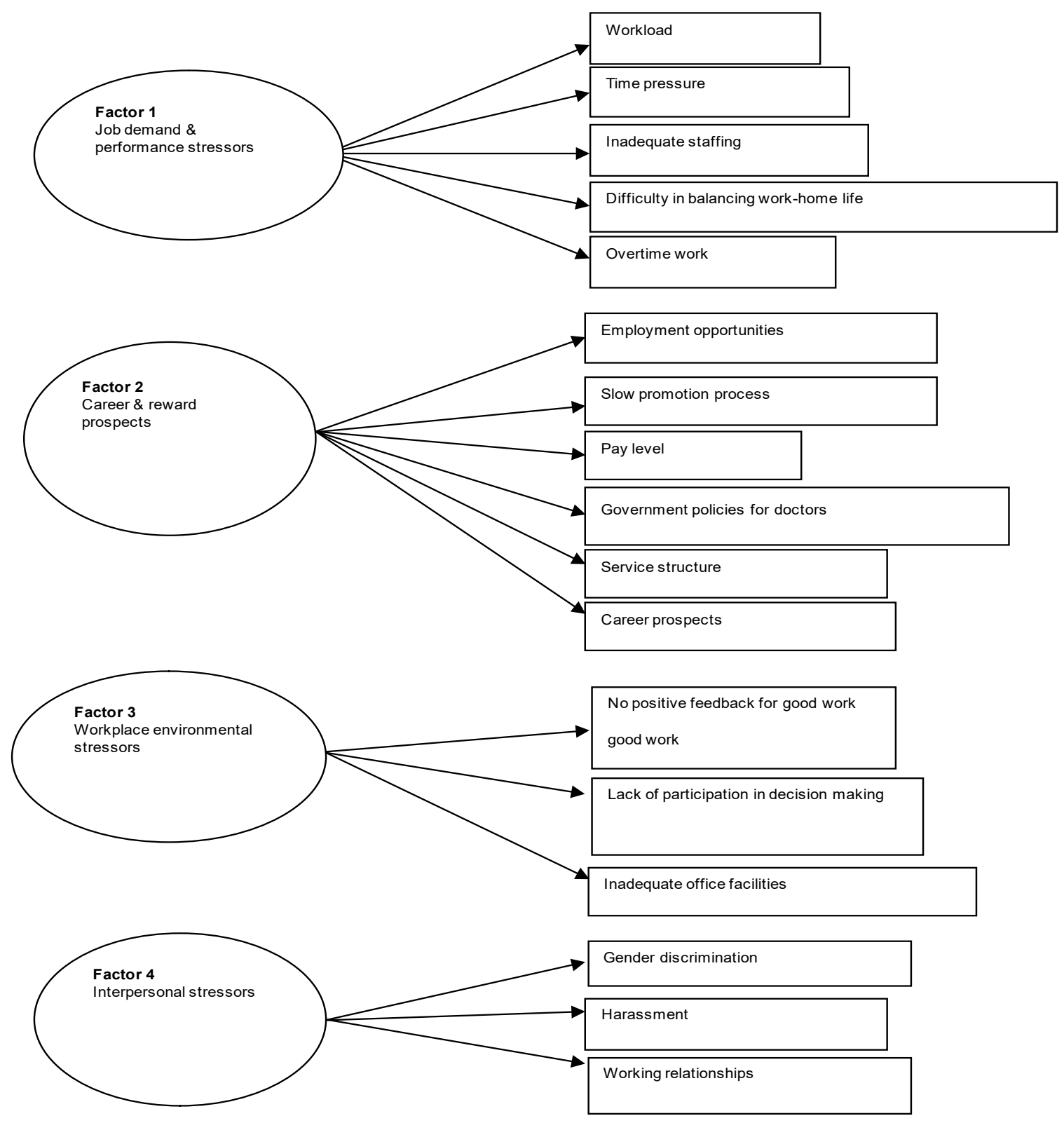

Figure 2: The underlying structure of the four extracted stress factors

\section{Ranking of factors}

Figure 3 shows us the ranking in decreasing order of importance:
1 "Career and reward prospects"

2 "Workplace environmental stressor".

3 "Job demand and performance stressor"

4 "Interpersonal stressor". 


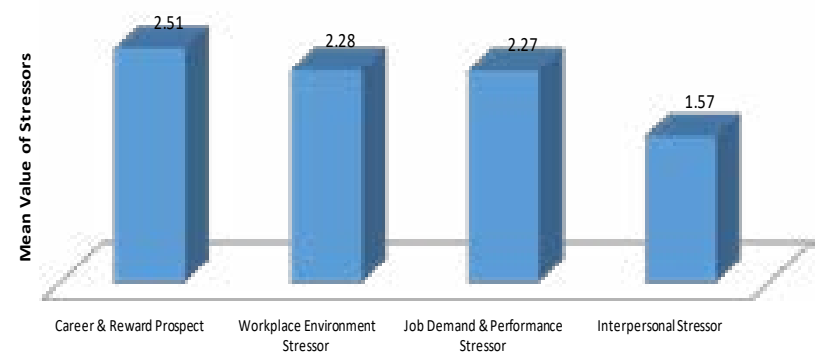

Stress Factors

Figure 3: Overall ranking of stressors

Table 4. Ranking of stressors with respect to positions

\begin{tabular}{|c|c|c|c|c|c|}
\hline & Consultant & Specialist registrar & P.G. Trainee & Demonstrator & Medical officer \\
\hline $\begin{array}{l}\text { Most stressful } \\
\text { factor } \\
\text { (Mean value) }\end{array}$ & $\begin{array}{c}\text { Workplace } \\
\text { environment } \\
\text { stressors }(2.95)\end{array}$ & $\begin{array}{c}\text { Career \& reward } \\
\text { stressors }(3.80)\end{array}$ & $\begin{array}{c}\text { Career \& } \\
\text { reward stressors } \\
(3.50)\end{array}$ & $\begin{array}{c}\text { Career \& } \\
\text { reward } \\
\text { stressors } \\
(3.12)\end{array}$ & $\begin{array}{c}\text { Career \& reward } \\
\text { stressors }(3.70)\end{array}$ \\
\hline $\begin{array}{l}\text { Very stressful } \\
\text { factor } \\
\text { (Mean value) }\end{array}$ & $\begin{array}{c}\text { Career \& } \\
\text { reward } \\
\text { stressors }(2.84)\end{array}$ & $\begin{array}{c}\text { Workplace } \\
\text { environment } \\
\text { stressors } \\
(3.60) \\
\end{array}$ & $\begin{array}{c}\text { Job demand } \\
\& \text { performance } \\
\text { stressors }(3.48)\end{array}$ & $\begin{array}{c}\text { Workplace } \\
\text { environment } \\
\text { stressors }(2.87)\end{array}$ & $\begin{array}{c}\text { Job demand } \\
\& \text { performance } \\
\text { stressors }(3.49)\end{array}$ \\
\hline $\begin{array}{l}\text { Stressful } \\
\text { factor } \\
\text { (Mean value) }\end{array}$ & $\begin{array}{c}\text { Job demand } \\
\text { \& performance } \\
\text { stressors } \\
(2.67)\end{array}$ & $\begin{array}{c}\text { Job demand } \\
\text { \& performance } \\
\text { stressors (3.52) }\end{array}$ & $\begin{array}{c}\text { Workplace } \\
\text { environment } \\
\text { stressors }(3.23)\end{array}$ & $\begin{array}{c}\text { Job demand } \\
\text { \& performance } \\
\text { stressors }(2.45)\end{array}$ & $\begin{array}{c}\text { Workplace } \\
\text { environment } \\
\text { stressors }(3.44)\end{array}$ \\
\hline $\begin{array}{l}\text { Least } \\
\text { stressful } \\
\text { factor } \\
\text { (Mean value) }\end{array}$ & $\begin{array}{c}\text { Interpersonal } \\
\text { stressors } \\
(2.20)\end{array}$ & $\begin{array}{c}\text { Interpersonal } \\
\text { stressors } \\
(2.75)\end{array}$ & $\begin{array}{c}\text { Interpersonal } \\
\text { stressors } \\
(2.63)\end{array}$ & $\begin{array}{c}\text { Interpersonal } \\
\text { stressors } \\
(2.41)\end{array}$ & $\begin{array}{c}\text { Interpersonal } \\
\text { stressors } \\
(2.65)\end{array}$ \\
\hline
\end{tabular}

\section{Discussion}

There are different contributing factors behind the high level of stress for medical practitioners. Our study showed that the major contributing factor is "career \& reward prospects" (Fig.3). In Pakistan, strikes by young doctors are carried out to protest against lack of service structure, job security and low pay. Due to lack of planning and poor governance, there are nt even enough vacancies to accommodate all the postgraduate (PG) trainees on the payroll in public sector hospitals. As a result, they have to work without a pay for the sake of completion of their postgraduate training. If a doctor has limited options for career growth and if they do not get enough pay then not only is the quality of medical care adversely affected, but also it may lead to brain drain. The current unrest among doctors or healthcare workers is the result of an inability of the government to deliver in terms of stated promises, which involve job structures, employment opportunities and reward systems.

"Workplace environmental stressor"- the second stressful factor for health professionals in Pakistan (Fig.3) ${ }^{17}$. Peer support, appreciation, positive feedback on good work and participation in decision making are the indicators of a supportive work environment which lacks in most of the hospitals. The working environment in hospitals, especially in public hospitals, does not meet the values and 
aspirations of health professionals. Medical professionals become dissatisfied with these conditions and respond unfavourably to these restrictive work environments.

"Job demand and performance stressor" came next in the list (Fig.3). Qualified MBBS doctors are made to work 102 hours a week without off days, including postgraduate trainees and medical officers. Long working hours damage the well-being of doctors and also affect the patient care. Work schedules for doctors are unregulated and many doctors work more than contracted hours. Working hours have become a hot topic of discussion due to the potential negative results of sleep deprivation on both healthcare professionals and their patients. Many doctors went to the court to ensure that government and hospitals should control or manage their unlawful rules and regulations related to the working schedules of doctors.

"Interpersonal stressor" was the last among stress factors (Fig.3). Individuals have the need to be respected and to be valued by others. Healthy relationships at work place give a sense of security and also enhance job satisfaction. Unfortunately, work place harassment is a serious issue but remains underreported due to the socially tabooed nature of the problem in Pakistan. Our study showed that gender discrimination is part of the stressors. To most people, there seems to be no gender discrimination in the world of doctors but this is untrue. In Pakistan, $80 \%$ to $90 \%$ of leadership roles in medicine are filled by men. Even in the case of salaries, there are known and unknown causes for why gender discrimination continues to occur in medicine. The administrative slackness on part of the hospitals, provincial governments, health personnel and employers affects thousands of medical health professionals. It is the need of an hour to maintain an environment such that trust and positive feelings of doctors are maintained for the well-being of healthcare professionals.

\section{Conclusion}

The present study showed that "career \& reward" is the most stressful factor followed by "workplace environment", "job demand \& performance" and "interpersonal stressor". Given the existing situation in developing countries like Pakistan, it is essential to address these stressors in order to decrease the migration of medical healthcare professionals, to reduce the shortage of medical practitioners and to minimize the wastage of already limited resources. These factors can present opportunities for interventions and aid in the creation of new policies and strategies. Stress does not remain static and is dependent on many continuously changing factors. Some variables cause more stress while some variables cause less stress. In order to enhance the ability of doctors to perform their jobs in a better way, the concerning authorities should eliminate stress for healthcare professionals.

\section{Recommendations and suggestions}

Based on the above findings, the following recommendations are provided:

\section{Career and reward}

The Government should revise the salary and service structure of the medical practitioners in Pakistan.

Postgraduate vacancies should be increased to match with a load of graduating medical students.

The Government should implement a proper performance management system to tackle the issues related to feedback and promotions of doctors.

There should be an equal chance of promotion, pay rise in a fair way without gender discrimination.

Promotions should be based on transparent appraisals and evaluations.

\section{Workplace environment}

Hospital administration should have zero tolerance policies against harassment of medical practitioners.

There is need for the supportive and participative style of management which enhances respect for juniors or co-workers.

\section{Job demand and performance}

There is need to have an effective record of external migration of doctors and also to keep the record of factors which influence their decision for migration. This would increase the knowledge base of the different determinants of migration, brain drain, dissatisfaction and would also help in providing ways to ensure talent is retained.

The older policies should be revised to include the solutions to work place problems faced by healthcare professionals in Pakistan.

All the policies which are planned should be implemented effectively and efficiently and their audits should be conducted annually or biannually to evaluate the results. 


\section{Interpersonal stressors}

Political influenced interference in transfers, posting and promotions should be monitored.

Management should focus on training programs for doctors to control harassment issues.

Security should be provided to doctors for their personal safety especially to female doctors performing night duties.

\section{Conflict of ineterst}

None declared.

\section{References}

1. Cozens F. Doctors, their wellbeing, and their stress. BMJ. 2003;326-670.

2. Kuhlmann SM, Huss M, Bürger A, Hammerle F. Coping with stress in medical students: results of a randomized controlled trial using a mindfulness-based stress prevention training (MediMind) in Germany. BMC Med Educ. 2016;16.

3. De Vibe M, Solhaug I, Tyssen R, Friborg O, Rosenvinge $\mathrm{JH}$, Sørlie T, et al. Mindfulness training for stress management: a randomised controlled study of medical and psychology students. BMC Med Educ. 2013;13.

4. Holm M, Tyssen R, Stordal KI, Haver B. Self-development groups reduce medical school stress: a controlled intervention study. BMC Med Educ. 2010;10.

5. Abdulghani HM, Al-Harbi MM, Irshad M. Stress and its association with working efficiency of junior doctors during three postgraduate residency training programs. Neuropsychiatr Dis Treat. Dove Press; 2015;11:3023-9 PubMed .

6. Aamir IS. Stress Level Comparison of Medical and Nonmedical Students: A Cross Sectional Study done at Various Professional Colleges in Karachi, Pakistan. Acta Psychopathol. iMedPub; 2017 Mar 31;03(02).

7. Hasan AA, elsayed S, Tumah H. Occupational stress, coping strategies, and psychological-related outcomes of nurses working in psychiatric hospitals. Perspect Psychiatr
Care. Wiley/Blackwell (10.1111); 2018 Feb 25;

8. Lazarus, R., Folkman S. Stress, appraisal and coping. New York Springe. 1984;

9. Shah M, Hasan S, Malik S, Sreeramareddy CT. Perceived stress, sources and severity of stress among medical undergraduates in a Pakistani medical school. BMC Med Educ. 2010;10(1):2 PubMed -8.

10. Imran,Nazish., Haider,Ijaz, Imran.,Iqtadar, Saima., Bhatti, Riaz M. Unhappy doctors in Pakistan: What are the causes and what can be done? I Imran | Pakistan Journal of Medical Sciences. Pakistan J Med Sci. 2011;27(2):244 PubMed -7 .

11. Aijaz Ahmed Sohag, Samina Memon, Mahmood-ur-Rahman, Masood Hussain Rao. A comparative study on factors causing job dissatisfaction among serving doctors at teaching hospitals of Hyderabad, Pakistan. Pak J Med Sci. 2012;28(4).

12. Pakistan Medical \&amp; Dental Council \&gt; Statistics [Internet]. [cited 2018 Oct 16]. Available from: http://www.pmdc.org.pk/statistics/tabid/103/default. aspx

13. Malik S, Farooqi, Nilofer Y. General and Sexual Harassment as Predictors of Posttraumatic Stress Symptoms among Female Health Professionals. World J Med Sci. 2014;10(1):43 PubMed -9.

14. Malik, Azam A, Yamamoto, Suzanna S, Souares A, Malik Z, Sauerborn R. Motivational determinants among physicians in Lahore, Pakistan. BMC Health Serv Res. 2010;10:1-11 PubMed .

15. Cerny, C.A., \& Kaiser HF. CA study of a measure of sampling adequacy for factor-analytic correlation matrices. Multivariate Behav Res. 1977;12(1):43-7.

16. Barkus, Yavorsky, Foster. Understanding and Using Advanced Statistics. Faculty of Health \& Behavioural Sciences. Papers. 2006;393.

17. Anjum A, Xu M, Ahmed, Faisal S, Samma, Faiz R. An Empirical Study Analyzing Job Productivity in Toxic Workplace Environments. Int J Environ Res Public Heal. 2018;15(5):1035. 